PCCP

CORRECTION

View Article Online

View Journal I View Issue

\title{
Correction: Ion collision cross section analyses in quadrupole ion traps using the filter diagonalization method: a theoretical study
}

Cite this: Phys. Chem. Chem. Phys., $2016,18,29642$

Ting Jiang, ${ }^{a}$ Muyi $\mathrm{He}^{\mathrm{a}}$ Dan Guo, ${ }^{\mathrm{a}}$ Yanbing Zhai ${ }^{\mathrm{a}}$ and Wei $\mathrm{Xu}{ }^{* \mathrm{ab}}$

DOI: $10.1039 / \mathrm{c} 6 \mathrm{cp} 90248 \mathrm{k}$

Correction for 'Ion collision cross section analyses in quadrupole ion traps using the filter diagonalization method: a theoretical study' by Ting Jiang et al., Phys. Chem. Chem. Phys., 2016, 18, 12058-12064.

www.rsc.org/pccp

In the published article, the author Muyi He was incorrectly spelt as Miyi He. The correct author list is shown above. The Royal Society of Chemistry apologises for these errors and any consequent inconvenience to authors and readers.

\footnotetext{
${ }^{a}$ School of Life Science, Beijing Institute of Technology Haidian, Beijing 100081, China. E-mail: weixu@bit.edu.cn; Tel: +86-010-68918123

${ }^{b}$ Key Laboratory of Convergence Medical Engineering System and Healthcare Technology, The Ministry of Industry and Information Technology,

Beijing Institute of Technology, Beijing 100081, China
} 